https://doi.org/10.31470/2706-7904-2020-15-149-159

\title{
РОЛЬ СЕМАНТИЧЕСКОГО СИНТАКСИСА В РАЗВИТИИ СВЯЗНОЙ РЕЧИ ДОШКОЛЬНИКОВ
}

\section{The Role of Semantic Syntax in the Development of Narratives in Preschool Children}

\author{
Hristo Kyuchukov \\ DSc. and Habilitation in Educational Science, Professor \\ University of Silesia (Poland) \\ hkyuchukov@gmail.com \\ http://orcid.org/0000-0002-1965-8908

\section{Oksana Ushakova} \\ DSc. in Pedagogy, Professor \\ Centre of Childhood of the «Institute of Studying Childhood, \\ Family and Education» of RAS (Russian Federation) \\ oxu@bk.ru

\section{Valentina Yashina} \\ DSc. in Pedagogy, Professor \\ Moscow State Pedagogical University (Russian Federation) \\ yashina.vi@mail.ru
}

\begin{abstract}
The aim of our research is to identify the role of semantic syntax in building a coherent monological narrative by preschoolers. The study was carried out with Russian monolingual preschool children from Moscow, Russia in the environment of the kindergarten, where the children get organised training on their language and cognitive development.

Twenty children between the age of 4 to 6 years old were tested with 2 series of pictures and the semantic syntax of the children's narratives were observed. The pictures are known form the developmental psychology as Theory of Mind series of pictures. (Seymour et al. 2015). They were used to collect narratives and in the narratives of the children the semantic syntax was observed specially. The compression between the age groups was done with the t-criteria.

The results showed that the children between 4-5 years old mainly listed the characters that were drawn in the picture, and their stories lacked logic. The older children's narratives - between 5-6 years old were distinguished by their completeness and logic, and they demonstrated an understanding of the characters' actions, the ability to finish a story, the ability to evaluate the heroes' actions and give the story a name.
\end{abstract}


The study shows that in the process of developing speech and verbal communication and getting to know others, it is necessary not only to enrich the subject matter and conceptual and logical content of words, but also to develop the ability to use the word as a unit of lexical and semantic language system. The Russian children achieve the ability to develop the logically well structured and semantically rich narratives in the age between 5-6 years old.

Keywords: semantic syntax, monological narrative, preschoolers

\section{Вступление \\ Introduction}

Изучение соотношения мысли, речи и языка в становлении языковой личности ребёнка-дошкольника предоставляет возможности для выявления закономерностей развития интеллектуальных, коммуникативных, речевых и языковых способностей в дошкольном детстве.

Проблема взаимодействия речи и мышления всегда находилась в центре внимания психолингвистических исследований, которые доказали, что формирование мышления и речи происходит в процессе практической деятельности, потому что язык, являясь средством общения людей, является и особым видом интеллектуальной деятельности (Выготский, 1982; Божович, 2006; Гальперин, 1957; Гумбольдт, 1984; Леонтьев, 1969; Лурия, 1979; Рубинштейн, 1946 и др.).

Как известно, в речи реализуются основные функции языка: коммуникативная (средство общения), когнитивная (познавательная), эмотивная (средство выражения чувств и эмоций). Российские и зарубежные психологи особое значение придают обозначающей, семантической функции речи, благодаря которой она является как формой существования мыслей, так и средством общения. Рубинштейн (1946) эти узловые свойства речи видел в ее связности. Конечно, основное развитие связной монологической речи связано с овладением письменной речью и относится к школьному возрасту, однако важную роль играет развитие связной устной речи, которая является фундаментом письменной речи и осуществляется в дошкольном детстве.

Центром развития языковой способности является семантический компонент, который лежит в основе лингвистического развития ребенка-дошкольника, включающего не только расширение объёма словаря, но и воспитание у детей внимания к содержательной стороне слова, его семантике, формирующего способность связывать между собой слова, предложения, части высказывания, поскольку в монологической речи семантика отдельного слова вступает во взаимодействие с семантикой всего текста. И здесь специальную роль играет 
семантический синтаксис, без которого невоможно развить способность к построению связного высказывания. Уточним, что эта способность включает и формирование умения понимать логику в развитии сюжета связного высказывания (Ушакова \& Лаврентьева, 2015; Сигал, 2015; Юрьева, 2017).

Синтаксис является высшим уровнем языка, потому что именно на этом уровне осуществляется главная функция языка - коммуникативная. Современная наука различает три аспекта синтаксиса: грамматический (традиционный), коммуникативный (передачи актуальной информации, с конкретной целью) и семантический, в котором предложение рассматривается как обозначение какой-то ситуации, фрагмента действительности. В семантическом плане предложение включает обозначение разных типов ситуаций: активное действие субъекта, свойство субъекта, существование явления и т.п. Основным средством выражения семантики синтаксической единицы является предикатная и предметная лексика, а самой существенной чертой предложения является его способность выражать мысль.

Семантический синтаксис, который формируется на основе взаимодействия с грамматическим и коммуникативным синтаксисом, показывает отношение высказывания к раскрываемой ситуации, а также помогает понять пути формирования смысла высказывания.

Все три аспекта рассматриваются исследователями в тесном взаимодействии. При этом вопрос о семантике предложений считается более сложным и не имеет однозначного решения. С одной стороны, в это понятие включается грамматическое значение вопроса, утверждения, побуждения, с другой стороны, в него еще включается и грамматическое значение словосочетаний, входящих в состав предложения. Отметим также связь грамматической (языковой, синтаксической) семантики и лексической семантики, которая представляет собой речевое, конкретное, индивидуальное значение той или иной синтаксической единицы, связанное с лексическим значением слов и словоформ. Иначе говоря, синтаксическая семантика является высшей ступенью обобщения лексической семантики. По Золотовой (2009), в зоне взаимодействия грамматики и лексики формируются структурно-семантические типы предложений и словосочетаний.

Синтаксис связной речи тесно переплетается со стилистикой, а понимание смысла и логика построения связного высказывания предполагают некоторое осознание коммуникативных и логических синтаксических средств. Именно этот аспект мы попытались проследить в исследовании, которое было проведено с воспитанниками московского дошкольного учреждения. Подчеркнем ту роль, которую играет когнитивный аспект в становлении языковых способностей дошкольника. В наших публикациях мы уже анализировали этот аспект, когда 
рассматривали понимание дошкольниками смысловой стороны слова. В следующей части мы проследим, как взаимосвязь языка и мышления влияет на формирование связности построения высказывания в контексте понимания логики развития сюжетной линии текста.

Известный немецкий ученый Гумбольдт (1984) писал, что интеллектуальная деятельность и язык представляют собой единое целое. Его высказывания о природе возникновения языковой способности у ребенка напрямую относятся к пониманию роли осознания явлений языка и речи в овладении родным языком, так как именно язык оказывает влияние на формирование системы понятий и системы ценностей. Эти его функции, а также способы образования понятий с помощью языка, считаются общими для всех языков. Основополагающие для лингвофилософской концепции В. фон Гумбольдта положения о взаимосвязи и единстве отношений мысли, речи и языка позволяют «познать сущность живой речи и составить верную картину живого языка» (Гумбольдт, 1984: 70).

Рассматривая проблему формирования понятий, Выготский говорил, что накопление ассоциаций и групп представлений не приводит к их образованию, «понятие невозможно без слов, мышление в понятиях невозможно вне речевого мышления» (Выготский, 1982: 133). Благодаря общению, взаимному пониманию, у ребенка возникает определенное значение слова, которое становится носителем понятия.

Все это дало некоторым исследователям основание считать, что слово почти никогда не имеет лишь одну, однозначную, предметную отнесенность, так как любое слово всегда многозначно и является полисемичным. Лурия (1979), анализируя идеи Выготского о том, как с возрастом расширяется осознание многозначности слова, подчеркивал, что психологически слово далеко не исчерпывается неизменной и однозначной «предметной отнесенностью». Каждое слово расширяет «семантическое поле», поэтому как процесс называния, так и процесс восприятия слова, следует рассматривать как сложный процесс выбора нужного «ближайшего значения слова». Этот выбор определяется многими факторами, среди которых есть как лингвистические, так и психологические моменты, например, включение слова в конкретную ситуацию. При этом важную роль играет функция слова, которую Выготский (1982) называл собственно значением, выходящим за пределы предметной отнесенности. Каждое слово не только обозначает предмет, не только выделяет признак, существенный для этого предмета, но и анализирует его. А самое главное, что слово несет сложную интеллектуальную функцию обобщения, которое участвует в важнейшей операции сознания. На основании этого Лурия (1979) делает вывод о том, что слово как орудие абстракции и обобщения является и клеточкой мышления. 
Анализирует он и другую сторону слова, являющуюся не только орудием мышления, но и средством общения. Передача информации является условием понимания, условием того, что человек, называя предмет, может передать свою мысль другому человеку. Значит, абстрагируя признак и обобщая предмет, слово становится орудием мышления и средством общения.

И, наконец, слово имеет «лексические функции», т.е. входит в известные классы смысловых отношений; оно располагает аппаратом, который создает потенциальную необходимость связи одних слов с другими, обеспечивая переход от называния слов к пониманию их семантических связей. Все это дает основание видеть в слове основное орудие формирования человеческого сознания, а также глубже понимать слово как средство речевой коммуникации.

Остановимся еще на одном положении, выдвинутом Выготским (1982), который писал, что в процессе развития ребенка развивается и понимание им значения слова, в котором он выделил смысловое значение (отнесение слова к предмету) и системное значение (на разных возрастных этапах в развитии значения слова стоят разные психологические процессы). Лурия (1979) отмечал, что отсюда следует сближение факта становления значения слова с фактом развития сознания, которое в процессе развития личности ребенка также существенно изменяется.

В раннем возрасте значение слова носит у ребенка аффективный характер, а к концу дошкольного возраста за значением слова кроются конкретные впечатления от реального практического наглядного опыта, изменяется и его сознание, а также элементарное осознание явлений языка и речи (Выготский, 1982; Леонтьев, 1969; Лурия, 1979; Сохин, 2002).

Таким образом, понимание значения слова - это ключевой момент речевого онтогенеза. Овладеть значением слова - значит овладеть зафиксированным в языке способом отражения существенных для данного социума признаков предмета (явления) (Tomasselo, 2000; de Villiers \& Pyers, 2002, Kharchenko, 2017).

Цель исследования - выявить роль семантического синтаксиса в построении дошкольниками связного монологического высказывания.

\section{Методика исследования Techniques of the Research}

Наши исследования, проведенные с дошкольниками, воспитывающимися в разных условиях обучения, выявили некоторые особенности развития синтаксической стороны речи, логику развития связной монологической речи, взаимосвязь речевого и когнитивного развития дошкольников. При этом особое внимание мы уделяли и 
Psycholinguistics in a Modern World - 2020. Proceedings of the 15th International Scientific and Practical Conference (Pereiaslav-Khmelnytskyi, 22-23 October, 2020)

выявлению эмотивной функции речи. Последняя рассматривается как непосредственная эмоциональная реакция на ситуацию, как передача информации о своем внутреннем состоянии.

В исследование приняли участие 20 детей: 10 мальчиков и 10 девочек в возрасте между 4-5 и 5-6 лет. В психолингвистике известно, что до 5 лет дети овладевают умениями связывать картинки в связный текст и мы хотели проверить, потверждается ли это положение в практике с русскоязычными детьми. Эксперимент был проведен на базе дошкольного образовательного учреждения №215 (г. Москва).

Основной задачей нашего исследования было выявление умения детей составлять связные рассказы по серии сюжетных картин. При этом дети должны были объяснить логику действий персонажей. Параллельно выявлялось умение дошкольников рассуждать и строить предложения разного типа, а также выявлялись и особенности семантического синтаксиса в построении дошкольниками связных высказываний.

Сначала дети рассматривали картинки. Затем давались задания, которые включали повествовательные и вопросительные предложения, целью которых было выявление понимания детьми содержания картинок и умения отразить это содержание в логически построенных высказываниях. При этом дети должны были объяснить логику действий персонажей. Заметим, что в этих заданиях четко выявилась логика построения высказываний, отражающих действия персонажей, т.е. связь когнитивного и языкового развития ребенка.

Как стимульный материал были использованы 2 серии картини (Seymour, Roeper, deVilliers, J. \& deVilliers, P., 2005).

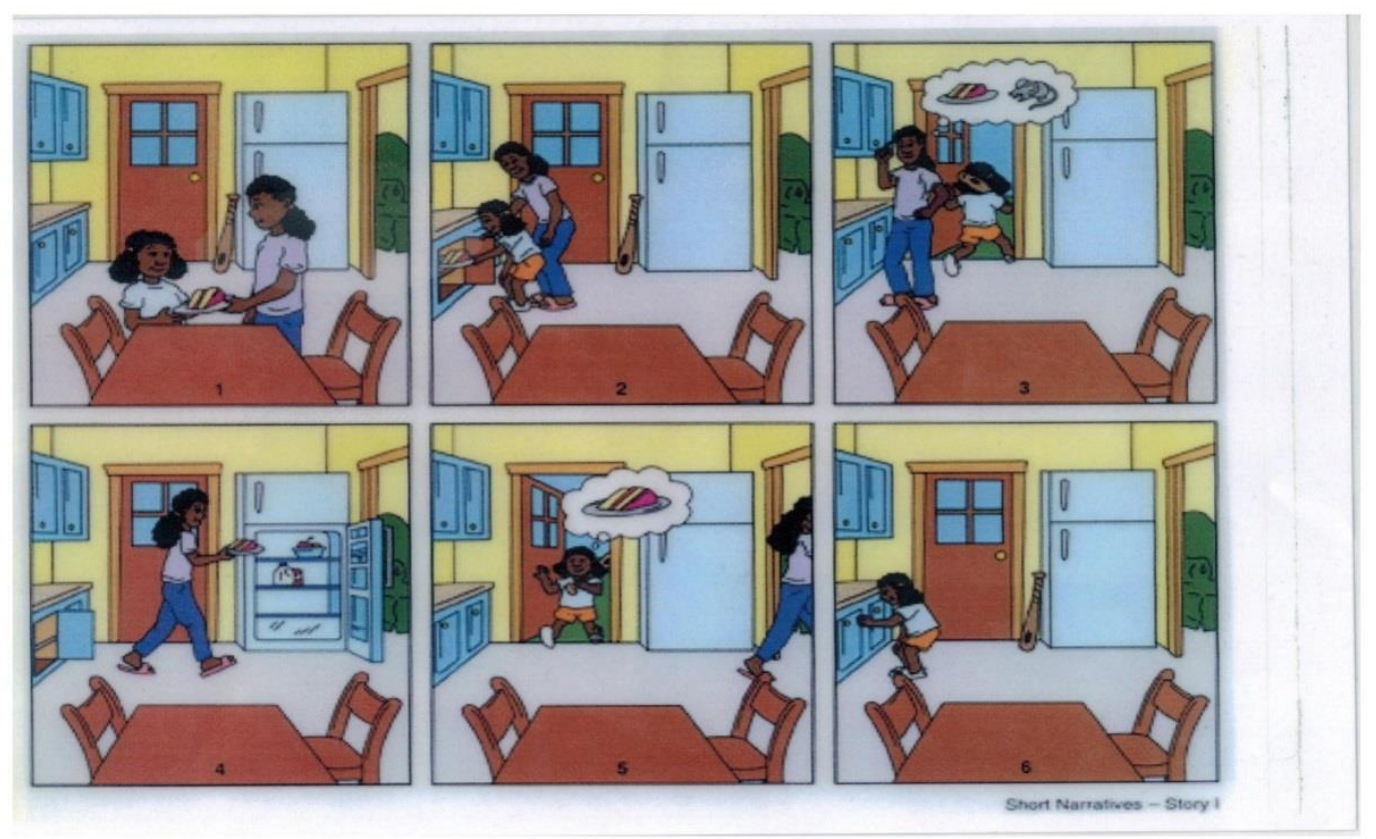




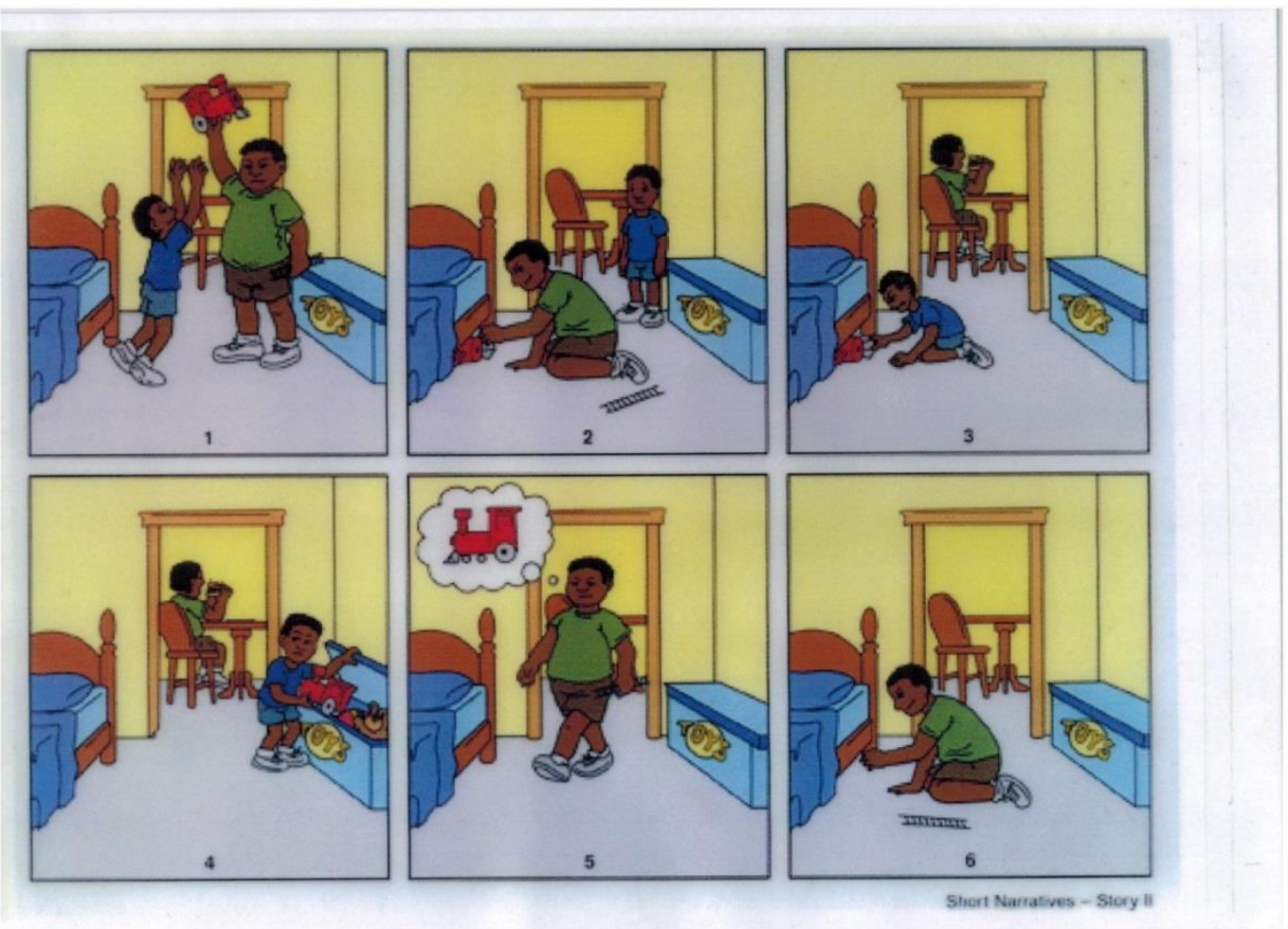

\section{Результаты \\ Results}

\section{Серия картинок на тему «Торт»}

Первые четыре картинки развивают сюжетную линию: мама испекла для дочери торт, они убирают его в шкаф. Девочка уходит гулять, а мама, подумав, что в шкафу могут быть мыши, убирает торт в холодильник. А 5 и 6 картинка требуют логического объяснения. Девочка, возвращаясь с прогулки, вспоминает про торт и ищет его в шкафу. Почему? Ответы на этот вопрос показывают, как ребенок понимает ситуацию, объясняет её и умеет рассуждать.

Дети старшего дошкольного возраста не только передали содержание картинок, выстраивая сюжетную линию в логической и временной последовательности, но и объясняли ситуацию, включая в ткань рассказа рассуждения, при этом они делали свои выводы. Некоторые дети придумывали конец рассказа, изображения которого на картинках нет.

Приведём пример рассказа ребенка шестого года жизни.

Рассказ испытуемого: (выполнил задание без помощи экспериментатора).

«Мама с дочкой приготовили торт. Потом они вместе поставили торт в шкаф. Девочка ушла гулять, а мама подумала, что в шкафу может быть мышка. И решила мама переложить торт в холодильник. Дочка пришла с прогулки и подумала: «Bот сейчас я буду есть вкусный торт!» Поила дочка искать торт в шкафу, куда 
она его поставила с мамой. Смотрит, а там его нет, но на самом деле торт был в холодильнике. И тогда девочка стала искать в холодильнике. И там его нашла и с удовольствием поела».

Ребенок дал название своему рассказу «Где же торт?». Умение дать точное название своему рассказу является одним из показателей связности монологического высказывания.

Гистограмма 1. Результаты построения рассказа на тему «Торт».

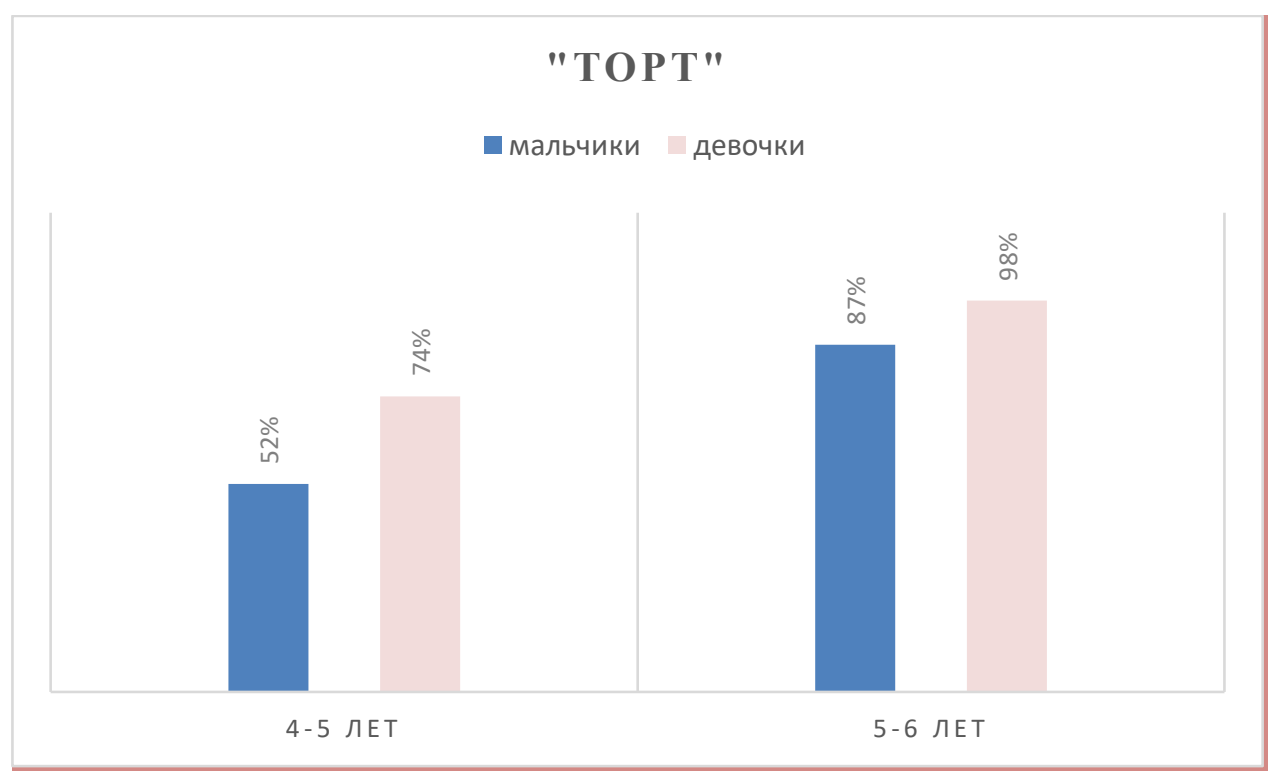

Несмотря на то что в группах есть разница между рассказами мальчиков и девочек они не статистические значимы. Дети в обеих возрастных группах справлялись хорошо $(\mathrm{t}>0.001)$

\section{Серия сюжетных картинок на тему «Игруика»}

Первые четыре картинки развивают сюжетную линию: младший брат хотел поиграть с паровозиком, но старший ему не дал и убрал его под кровать. Младший брат достал паровозик из-под кровати и убрал его в ящик с игрушками. Пятая и шестая картинки требуют от ребенка построить высказывание-рассуждение, чтобы объяснить и логически завершить происходящее. Почему старший брат пошел сразу к кровати? (Он помнил, куда он положил игрушку). А почему он её не нашел? (Младший брат спрятал паровозик в ящик с игрушками).

Дети пятого года жизни, в основном, перечисляли персонажей, которые были нарисованы на картинке, а в их рассказах отсутствовала логика.

У детей старшего дошкольного возраста рассказы отличались полнотой и логикой изложения, при этом они продемонстрировали понимание действий 
персонажей, умение закончить рассказ, дать оценку действиям героев и дать называние рассказу.

Приведём пример.

Рассказ испытуемого (выполнил задание без помощуи экспериментатора).

«Два мальчика играли в комнате. Тот, мальчик, который выше, держал паровозик наверху в руке, а другой мальчик (поменьше) хотел с ним почрать. $A$ старший не давал мальчику, который поменьше, с паровозиком играть. Мальчик $в$ зеленой майке хотел спрятать паровозик. И спрятал его под кровать. А потом он ушел в другую комнату читать, а мальчик в синей футболочке полез под кровать $и$ нашел паровозик под кроватью. Дальше он положил паровозик в икафчик $с$ игрушками. И вот в комнату зашел мальчик в зеленой майке и подумал: «Сейчас я достану паровозик и буду играть!» Посмотрел под кровать, а его там нет. И задумался: «Может его достал мой брат? И положил туда, где лежат все игрушки?». Он тогда залез в синий шкаф и нашел его там».

Ребёнок дал название своему рассказу - «Паровозик».

Гистограмма 2. Результаты построения рассказа на тему «Игрушка»

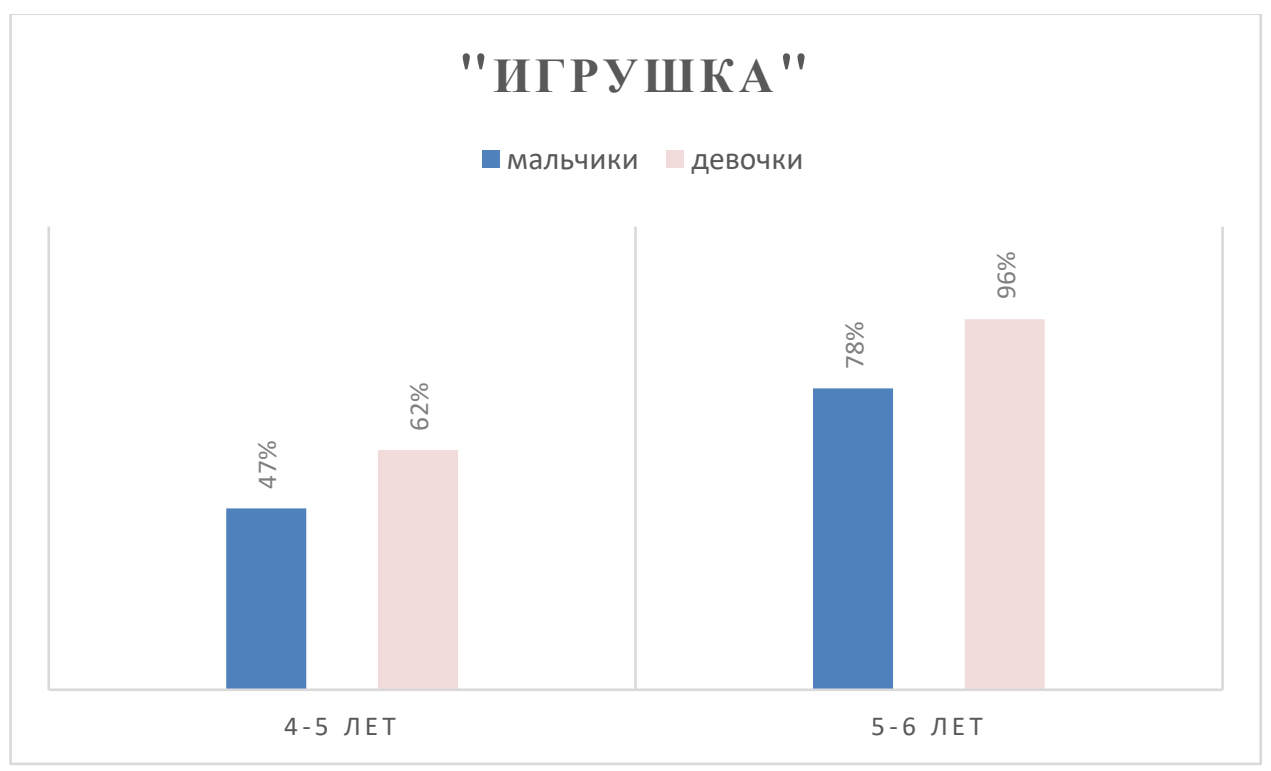

Как видно из таблицы, девочки лучше справлялись с заданием, чем мальчики. Разница между девочками и мальчиками статистически значима (при $\mathrm{t}>0.001$ ).

Наши исследования помогли нам сформулировать некоторые особенности построения связного высказывания, составленного детьми по серии сюжетных картин, которые включали задание на выявление умения дошкольников логически мыслить и передавать свои объяснения и рассуждения в связных высказываниях. Эти исследования подтвердили также положения о взаимосвязи коммуникативного и 
семантического, когнитивного и языкового аспекта в развитии связной монологической речи дошкольников.

В настоящей статье мы рассматривали высказывания детей с точки зрения понимания логических связей, представленных в действиях персонажей через серию сюжетных картин и роль семантического синтаксиса в построении вычказывания.

\section{Выводы \\ Conclusions}

Роль слова как основной единицы языка, его значение в психическом развитии ребенка определяют сущность развития языковой способности.

Материалы исследования показали, что в процессе развития речи и речевого общения, ознакомления с окружающим необходимо не только обогащать предметновещественное и понятийно-логическое содержание слов, но и развивать умения пользоваться словом как единицей лексико-семантической системы языка.

Теоретический анализ, экспериментальное изучение работы над смысловой стороной слова дошкольников разных возрастов указывают на необходимость целенаправленного воздействия на разные стороны лексических значений слов в их речи: номинативной функции, обобщений, заложенных в слове, лексикосемантических связей слов и употребления их в связных высказываниях.

В дальнейших исследованиях мы предполагаем выявить особенности построения предложений в рассказывании по серии сюжетных картин и выстраивание структуры рассказа в логической и временной последовательности, а также роль семантического синтаксиса в развитии связной речи дошкольников.

\section{Литература \\ References}

Божович, Л.И. (2006). Речь и практическая интеллектуальная деятельность ребёнка (экспериментально теоретическое исследование). Культурно-историческая психология, $1-3$.

Выготский, Л.С. (1982). Мышление и речь. (1-6 т.). (Т. 2). Москва: Педагогика.

Гумбольдт, В. (1984). Избранные труды по общему языкознанию. Москва.

Золотова Г. А. (2010). Коммуникативные аспекты русского синтаксиса. (6-е изд.). Москва: УРСС.

Кючуков, Хр., Ушакова, О.С., \& Яшина, В.И. (2015). Изучение особенностей речевого развития детей дошкольного возраста в условиях билингвизма. Psycholinguistics Psiholingvistika, 18(1), 50-58.

Леонтьев, А.А. (1969). Язык, речь, речевая деятельность. Москва: Просвещение. 
Лурия, А. Р. (1979). Язык и сознание. Москва: МГУ.

Рубинштейн, С.Л. (1946). Проблемы общей психологии. Москва.

Сигал, К.Я. (2015). Синтаксис связной речи: проблемы и перспективы. Bonpocbl психолингвистики, 4(26), 162-168.

Сохин, Ф.А. (2002). Психолого-педагогические основы развития речи дошкольников. Москва: МОДЭК.

Ушакова, О.С. (2018). Закономерности овладения родным языком: развитие языковых $u$ коммуникативных способностей в дошкольном детстве. Москва: Сфера.

Ушакова, О.С., \& Лаврентьева, А.И. (2015) Роль семантического компонента в развитии языковой способности дошкольников. Педагогическое образование и наука, 3, 5-20.

Ушакова, О.С., \& Яшина, В.И. (2019). Семантический компонент развития языковой способности в дошкольном детстве. Артамонова Е.И. \& Ушакова О.С. (Ред.), Язык $и$ актуальные проблемы образования (2. Москва, 18 января 2019), (с. 50-57). Москва: МГОУ, МАНПО.

Юрьева, Н.М. (2017). Интерактивний подход в изучение становления нарратива в онтогенезе речи. Филологические речи. Вопросьи теории и практики, 12(78), 178.

Яшина, В.И., \& Алексеева, М.М. (2017). Теория и методика развития речи детей. Москва: Академия.

de Villiers, J., \& Pyers, J.E. (2002) Complements to cognition: A longitudinal study of the relationship between complex syntax and false-belief-understanding. Cognitive development, 17(1), 1037-1060.

Kharchenko, N. (2017) Language personality of a preschool child: features of development in the process of listening. Psycholinguistics - Psiholingvistika, 21(1), 171-185.

Kyuchukov, H., Ushakova, O.S., \& Yashina, V.I. (2015). Bilingual and multicultural education in Russian kindergartens. Intercultural Education, 26(3), 248-251. https://doi.org/10.1080/14675986.2015.1048960

Seymour, H., Roeper, T., deVilliers, J., \& deVilliers, P. (2005) DELV. Psychology Press.

Tomasselo, M. (2000). Do young children have adult syntactic competence? Cognition 74(3), 209253. https://doi.org/10.1016/S0010-0277(99)00069-4

$\mathrm{Wu}$, Ch. et al. (2016) Preschoolers' brains rely on semantic cues prior to the mastery of syntaxduring sentence comprehension. NeuroImage, 126(1), 256-266. https://doi.org/10.1016/j.neuroimage.2015.10.036 